\title{
A Formação Sete Lagoas em sua área-tipo: fácies, estratigrafia e sistemas deposicionais
}

\author{
Lucieth Cruz Vieira ${ }^{1}$, Renato Paes Almeida ${ }^{2}$, Ricardo I. F. Trindade ${ }^{1}$, \\ Afonso C. R. Nogueira ${ }^{3}$ \& Liliane Janikian ${ }^{1}$
}

\begin{abstract}
Resumo Estudos detalhados de fáceis sedimentares e empilhamento estratigráfico de 12 seções em minas e corte de estrada, ao longo de um perfil de $80,5 \mathrm{~km}$, conduziram ao reconhecimento de 11 fácies sedimentares da Formação Sete Lagoas, 2 fácies do Conglomerado Carrancas e 3 fácies na porção basal da Formação Serra de Santa Helena. Essas fácies compõem 9 associações de fácies, as quais correspondem ao registro de 3 seqüências deposicionais. As seqüências estratigráficas descritas são caracterizadas por tratos de sistema transgressivo e mar alto, com preservação secundária de um trato de sistema de mar baixo. Duas das três seqüências reconhecidas estão associadas à sucessão carbonática da Formação Sete Lagoas, enquanto a última seqüência, sobreposta aos carbonatos, corresponde ao registro siliciclástico da Formação Serra de Santa Helena. A distribuição estratigráfica das associações de fácies revela uma transição de ambientes de águas rasas a Oeste da área estudada para ambientes de águas mais profundas em direção a Leste. Um modelo de rampa carbonática, mostrando os diferentes estágios de evolução das seqüências, é apresentado como proposta de interpretação para os dados faciológicos e estratigráficos obtidos para os depósitos da Formação Sete Lagoas na região homônima e proximidades.
\end{abstract}

Palavras-chave: Formação Sete Lagoas, análise de fácies, estratigrafia, Neoproterozóico.

\begin{abstract}
The Sete Lagoas Formation at the Type Area: Facies, Stratigraphy and Depositional Sistems. Detailed facies analysis and stratigrafic measurement, description and interpretation of 12 quarry and road-cut sections across a $80.5 \mathrm{~km}$ long transect lead to recognition of 11 sedimentary facies of the Sete Lagoas Formation, 2 facies of Carrancas Conglomerado and 3 facies at the base of the Santa Helena Formation. Such facies are comprised into 9 facies associations regarding 3 depositional sequences. The described stratigraphic sequences are characterized by transgressive and higstand systems tracts, with minor preservation of one lowstand system tract, being the first two correlated with the carbonatic Sete Lagoas Formation and the last to the overlying siliciclastic Serra de Santa Helena Formation. The stratigraphic distribution of facies associations reveals an evolution from a $\mathrm{CaCO}_{3}$ oversaturated carbonate ramp to a storm dominated ramp that progressively becomes distally steepened, and finely a clastic-dominated margin in the last sequence. The geographic distribution of facies associations reveals a transition from shallow water environments in the West to deeper water environments towards the East of the studied area.
\end{abstract}

Keywords: Sete Lagoas Formation, facies analysis, stratigraphy, Neoproterozoic.

INTRODUÇ̃̃O O fim do Pré-Cambriano foi marcado por eventos glaciais rapidamente sucedidos por uma ampla sedimentação de carbonatos (capas carbonáticas), caracterizando severas mudanças climáticas que provavelmente tiveram importante papel para a explosão de vida do Cambriano (Hoffman \& Schrag 2002). Dados paleomagnéticos de rochas glaciais do Neoproterozóico mostram que as calotas de gelo alcançaram latitudes equatoriais naquele período geológico, o que implica que essas glaciações foram as mais extremas na história da Terra (Evans 2000). Os depósitos glaciais desse período apresentam ampla distribuição geográfica, estando presentes em todos os continentes, e com- preendem tanto depósitos continentais quanto marinhos. Eles apresentam por vezes intercalações de formações ferríferas bandadas, atestando a permanência do oceano em estado anóxico por um tempo significativo. As capas carbonáticas nos dão uma indicação das mudanças ambientais ocorridas após as glaciações neoproterozóicas. Elas formam seqüências transgressivas associadas à subida do nível do mar pós-glacial, e a maioria delas compreende uma unidade dolomítica basal com valores negativos de isótopo de carbono coberta por calcários (Kennedy 1996). Estruturas sedimentares anômalas são normalmente encontradas nos primeiros metros da seqüência de capa carbonática, incluindo tubos verticais,

1 - Departamento de Geofísica, Instituto de Astronomia, Geofísica e Ciências Atmosféricas, Universidade de São Paulo, São Paulo (SP), Brasil.E-mail: lucieth@iag.usp.br, rtrindad@iag.usp.br, lijanikian@yahoo.com.br

2 - Departamento de Geologia Sedimentar e Ambiental, Instituto de Geociências, Universidade de São Paulo, São Paulo (SP), Brasil. Email: rpalmeid@usp.br

3 - Departamento de Geociências, Universidade Federal do Amazonas, Manaus (AM), Brasil. E-mail: anogueira@ufam.edu.br 
laminação estromatolítica e megaripples associadas com depósitos de plataforma rasa, bem como precipitados de água profunda, representados por crostas e leques de cristais pseudomorfos de aragonita (p.ex. Peryt et al. 1990, Kennedy 1996, Kennedy et al. 2001, Hoffman and Schrag 2002, James et al. 2001, Sumner 2002, Allen \& Hoffman 2005). Descrições completas de capas carbonáticas incluindo estratigrafia, sedimentologia e isótopos, foram feitas recentemente para a Austrália, Namíbia, Noroeste do Canadá, Sul da China, Svalbard e Amazônia (Narbonne \& Aitken 1995, Kennedy 1996, Hoffman et al. 1998, James et al. 2001, Jiang et al. 2004, Halverson et al. 2004, Nogueira et al. 2003, Alvarenga et al. 2004).

$\mathrm{Na}$ porção central do Brasil, carbonatos do Grupo Bambuí têm sido reportados capeando rochas glaciais dos Grupos Macaúbas e Jequitaí (Costa \& Branco 1961, Dardenne 1978). Embora um número considerável de estudos isotópicos tenha sido efetuado nessas unidades até então (Peryt et al. 1990, Misi \& Veizer 1998, Babinski et al. 1999, Santos et al. 2000, Alvarenga et al. 2004), ainda faltam análises detalhadas de fácies e empilhamento estratigráfico. A fim de contribuir para o preenchimento dessa lacuna, são apresentados aqui dados de análises de fácies e estratigráfica de detalhe, referentes à unidade basal do Grupo Bambuí (Formação Sete Lagoas). Foram estudadas 16 seções localizadas na área clássica da referida unidade, em torno das cidades de Sete Lagoas e Vespasiano, na porção centro-sul do estado de Minas Gerais (Fig. 1a). Esses resultados fornecem informações sobre as mudanças nos ambientes deposicionais, ocorridas após as glaciações neoproterozóicas, na porção sul do Cráton do São
Francisco.

ARCABOUCO GEOLÓGICO A Bacia de São Francisco cobre mais de $300.000 \mathrm{~km}^{2}$ do Cráton do São Francisco. Essa bacia contém uma extensa cobertura sedimentar de rochas clásticas e carbonáticas neoproterozóicas (Supergrupo São Francisco), compreendendo uma unidade glacial basal (Conglomerado Carrancas/ Grupo Macaúbas/Formação Jequitaí) coberta por uma espessa sucessão carbonática (Grupo Bambuí) (Dardenne 1978, Karfunkel \& Hoppe 1988, Uhlein et al. 1999, Martins-Neto et al. 2001). A unidade glacial basal compreende diamictitos, conglomerados clasto-suportados, arenitos maciços e ritimitos de pelitos-siltitos depositados em ambiente glacio-marinho (Jequitaí) e retrabalhados por fluxo gravitacional (Macaúbas). Uma lente de conglomerado polimítico com matriz carbonática (Carrancas) depositado diretamente sobre gnaisses paleoproterozóicos também tem sido interpretada como de origem glacial (Martins-Neto et al. 2001). O Grupo Bambuí é dividido em cinco unidades (Fig. 1b): (i) Formação Sete Lagoas composta de dolomitos, calcários e pelitos com estromatólitos bem preservados; (ii) Formação Serra de Santa Helena, formada por folhelhos, siltitos e secundariamente arenitos; (iii) Formação Lagoa do Jacaré composta de siltitos, margas e calcário preto; (iv) Formação Serra da Saudade que inclui folhelhos verdes, siltitos e lentes de calcário; e (v) Formação Três Marias, que ocupa o topo da sucessão e compreende siltitos e arcóseos depositados em ambientes aluvial a marinho-raso.

O Grupo Bambuí é afetado por deformação fraca moderada como resultado da atividade tectônica ao a)

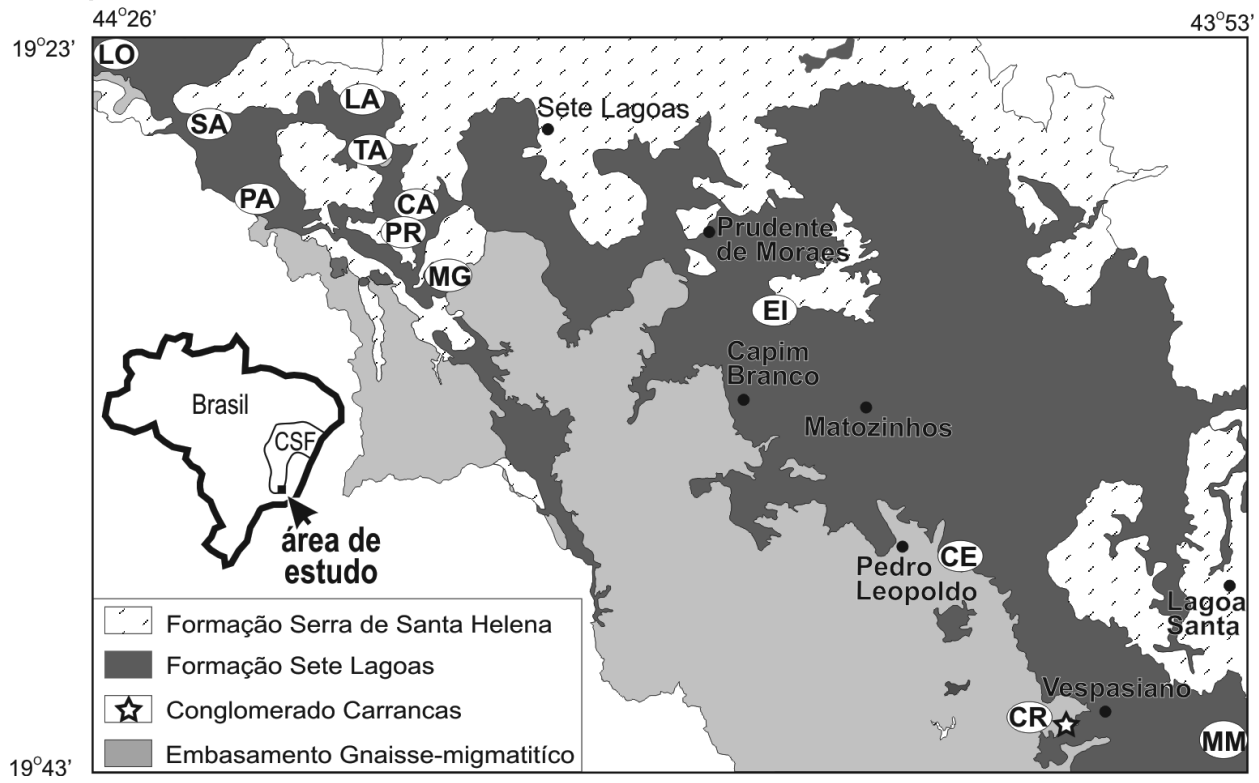

b)

\begin{tabular}{|c|c|c|}
\hline & Litoestratigrafia & \\
\hline & $\begin{array}{l}\text { Formação } \\
\text { Três Marias } \\
\text { (Siltitos verdes } \\
\text { e arcóseos) }\end{array}$ & \\
\hline & $\begin{array}{c}\text { Formação } \\
\text { Serra da Saudade }\end{array}$ & \\
\hline & $\begin{array}{c}\text { (Folhelhos verdes, pelitos, } \\
\text { siltitos e lentes de } \\
\text { calcário) }\end{array}$ & \\
\hline & Formação & \\
\hline & (Siltitos, margas e & \\
\hline & Formação & \\
\hline & $\begin{array}{c}\text { Serra de Santa } \\
\text { (siltitos, folhelhos } \\
\text { e lentes de calcário) }\end{array}$ & \\
\hline & \begin{tabular}{l}
\multicolumn{1}{c}{ Formação } \\
Sete Lagoas \\
(Dolomitos, calcários, \\
siltitos e pelitos)
\end{tabular} & 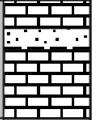 \\
\hline & $\begin{array}{c}\text { Carrancas } \\
\text { (Conglomerado) }\end{array}$ & 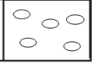 \\
\hline
\end{tabular}

Figura 1 - a) Mapa geológico com a localização das seções estudadas: CR - Carrancas, CA - mina Canaã, LO Lontra, SA - mina Sambra, PA - mina Paraíso; TA - mina Tatiana, MG - Mina Mata Grande, PR - posto da Polícia Rodoviária, EI - mina Eincal, CE - mina Cauê, MM - mina Mineral Mix; b) Litoestratigrafia do Grupo Bambuí baseada em Dardenne (1978). 
longo das faixas de dobramentos Brasilianas (Brasília, Araçuaí e Rio Preto), levando alguns autores a sugerir que o Grupo Bambuí representa sedimentação em uma bacia do tipo foreland da orogenia Brasiliana (p.ex. Marshak \& Alkmin 1989). Perfis sísmicos publicados recentemente (Romeiro-Silva \& Zalán 2005) mostram que não há espessamento significativo do Grupo Bambuí de leste para oeste e nem mudanças claras de fácies que possam suportar um modelo de bacia do tipo foreland. Além disso, os perfis sísmicos indicam que a seqüência Bambuí foi realmente depositada antes da Orogenia Brasiliana.

Uma idade máxima de sedimentação de ca. 900Ma para as rochas do Grupo Macaúbas é fornecida por datações U-Pb (SHRIMP) de zircões de depósitos glaciais (Pedrosa-Soares et al. 2000). Idades similares foram obtidas para um dique (U-Pb em zircão e badeleyta) que corta o Supergrupo Espinhaço, mas não intrude os sedimentos glaciais (Machado et al. 1989). Várias tentativas de datação direta das rochas do Grupo Bambuí pelos métodos $\mathrm{Pb}-\mathrm{Pb}$ e U-Pb não têm obtido sucesso. A maioria das idades varia de 550 a $500 \mathrm{Ma}$, sendo contemporâneas ou mesmo mais jovens que o pico de atividade tectônica que afetou as rochas carbonáticas (Babinski et al. 1999, D'Agrella-Filho et al. 2000). Apenas duas isócronas ${ }^{207} \mathrm{~Pb}^{206} \mathrm{~Pb}$, obtidas da Formação Sete Lagoas, são mais velhas que $600 \mathrm{Ma}$, podendo representar a idade de deposição. Uma idade de $686 \pm 69$ Ma foi obtida por Babinski et al. (1999) e fornece uma idade deposicional mínima para os carbonatos. Outro dado de $740 \pm 22 \mathrm{Ma}$ foi recentemente obtido por Babinski et al. (2003) em uma seqüência carbonática bem preservada da parte sul da bacia (seção SA, Fig. 1a). O último dado é a melhor idade direta para delimitação da deposição dessas rochas. Essa idade está próximo às idades classicamente atribuídas ao intervalo glacial Sturtiano (Evans 2000) e é interpretada como a idade de deposição dessas rochas. A idade mínima de sedimentação é delimitada pela idade de metamorfismo de ca. $630 \mathrm{Ma}$ (idades $\mathrm{U}-\mathrm{Pb}$ em titanita e $\mathrm{Sm}-\mathrm{Nd}$ em granada na Faixa Brasília, obtidas por Pimentel et al. 1999). Isso impede a correlação da Formação Sete Lagoas com sucessões neoproterozóicas pós-glaciais mais jovens.

\section{FÁCIES, ASSOCIAÇÕES DE FÁCIES E AMBIEN-} TES DEPOSICIONAIS Este trabalho é baseado em descrições e medições estratigráficas detalhadas de seções de 12 minas e 1 corte de estrada compreendendo $80,5 \mathrm{~km}$ ao longo de um perfil WNW-ENE, entre as cidades de Sete Lagoas e Vespasiano. As descrições de fácies sedimentares e associações de fácies foram usadas para interpretar ambientes deposicionais e seus padrões de empilhamento, levando à caracterização de tratos de sistemas deposicionais e interpretação do arcabouço de seqüências estratigráficas. A maioria das seções mostra apenas deformação fraca e as relações estratigráficas entre as fácies não foram obliteradas por tectonismo. As camadas mais deformadas exibem finas bandas miloníticas associadas com o trend preferencial E das lineações de estiramento. Critérios cinemáticos, tais como mica-fish e relações de $\mathrm{S}-\mathrm{C}$, indicam transporte de leste para oeste.

Foram definidas 16 fácies com base em características texturais, composicionais e estruturas sedimentares (Tabela 1). Deve ser enfatizado, contudo, que para algumas fácies as texturas primárias foram obliteradas por neomorfismo e/ou dolomitização. De fato, calcários de granulação fina mostram uma textura microespática, a qual é interpretada como sendo originalmente micrítica. Por outro lado, calcário cristalino é interpretado como originalmente de granulação grossa, consideração reforçada pela presença esparsa de grãos terrígenos e fábrica peloidal fantasma (phantom peloidal fabric) nessas rochas. As diferentes fácies foram agrupadas em nove associações de fácies (AF), de acordo com seu significado paleoambiental dentro da Formação Sete Lagoas (Fig. 2), Conglomerado Carrancas e parte basal da Formação Serra de Santa Helena em contato com os carbonatos da Formação Sete Lagoas. As associações de fácies incluem: canais fluviais incisos (AF1), rampa carbonática supersaturada em $\mathrm{CaCO}_{3}$ (AF2); rampa carbonática média dominada por tempestade (AF3); rampa carbonática interna dominada por maré (AF4); rampa carbonática externa mista carbonato-siliciclástica (AF5); rampa carbonática interna estromatolítica influenciada por onda (AF6); rampa carbonática externa inclinada (AF7); offshore de plataforma siliciclástica (AF8) e shoreface prodelta - frente deltáica (AF9).

Canais fluviais incisos no embasamento (AF1) A sucessão mais inferior da área estudada compreende rocha carbonática com fragmentos siliciclásticos de granulação grossa, os quais consistem de seixos arredondados de carbonato, granito e quartzo, flutuando em uma matriz cuja composição varia entre micrito e microesparito com esparsos grãos de tamanho areia de quartzo, plagioclásio, biotita e litoclastos graníticos (Fig. 3a). Ao microscópio as partículas siliciclásticas mostram dissolução e substituição por carbonato micrítico, incluindo microvenulações, com a mesma composição da matriz, cortando os clastos, sugerindo uma origem secundária para o carbonato. Desconsiderando a substituição por carbonato, essas rochas são conglomerados polimíticos com gradação normal intercalados com lentes de arenitos seixosos com laminação paralela incipiente. Essa associação corresponde ao Conglomerado Carrancas, que ocorre sob carbonatos da Formação Sete Lagoas, em canais isolados incisos no embasamento paleoproterozóico.

Essa unidade compreende ciclos granodecrescentes ascendentes possivelmente de origem aluvial costeira. Não existem evidências claras de influência glacial nesses depósitos. Unidades glaciogênicas ou glacialmente influenciadas são reconhecidas abaixo do Grupo Bambuí em outras regiões do Cráton do São Francisco, incluindo a Formação Jequitaí (Uhlein et al. 1999, Martins-Neto et al. 2001) e as sucessões inferiores do Grupo Macaúbas (Karfunkel \& Hoppe 1988, Uhlein et al. 1999), mas essas unidades são prova- 
Tabela 1 - Resumo das fácies, estruturas sedimentares, processos de geração e associações de fácies da Formação Sete Lagoas, Conglomerado Carrancas e porção basal da Formação Serra de Santa Helena.

\begin{tabular}{|c|c|c|c|c|}
\hline Litologia/fácies & ESTRUTURAS & Processos & Interpretação & $\begin{array}{c}\text { Associação } \\
\text { de Fácies }\end{array}$ \\
\hline $\begin{array}{l}\text { Co n g lo m e r a d o } \\
\text { polimíticocimentado } \\
\text { por carbonato. } \\
\text { Seixos arredondados } \\
\text { a angulares }(\mathrm{Cm}) \\
\end{array}$ & maciço, gradação normal & $\begin{array}{l}\text { Deposição por correntes trativas, } \\
\text { cimentação diagenética. }\end{array}$ & \multirow[t]{2}{*}{$\begin{array}{l}\text { Canais incisados } \\
\text { no embasamento }\end{array}$} & \multirow[t]{2}{*}{$A F 1$} \\
\hline $\begin{array}{l}\text { Arenito seixoso com } \\
\text { cimento de calcita } \\
\text { (Ap) }\end{array}$ & $\begin{array}{l}\text { Laminação } \quad \text { plano-paralela } \\
\text { incipiente }\end{array}$ & $\begin{array}{l}\text { Deposição por correntes trativas em } \\
\text { canais incisos }\end{array}$ & & \\
\hline $\begin{array}{l}\text { Calcilutito } \\
\text { cementstone }(\mathrm{Mc})\end{array}$ & $\begin{array}{l}\text { Leques de cristais, crosta fibrosa } \\
\text { laminada }\end{array}$ & $\begin{array}{l}\text { Eventos de precipitação de } \\
\text { cristais de aragonita e crostas no } \\
\text { fundo do mar, concomitante com } \\
\text { precipitação de calcilutito associado } \\
\text { a água supersaturada em } \mathrm{CaCO}_{3} \mathrm{em} \\
\text { ambiente calmo. }\end{array}$ & \multirow[t]{2}{*}{$\begin{array}{l}\mathrm{R} \quad \mathrm{a} \quad \mathrm{m} \text { a } \\
\text { supersaturada } \\
\text { em } \mathrm{CaCO}_{3}\end{array}$} & \multirow[t]{2}{*}{$A F 2$} \\
\hline Calcilutito (Mp) & Laminação plano-paralela & Precipitação de calcilutito & & \\
\hline $\begin{array}{l}\text { Calcário cristalino } \\
(\mathrm{Ch})\end{array}$ & $\begin{array}{l}\text { Estratificação cruzada swaley e } \\
\text { hummocky. Marcas onduladas com } \\
\text { padrão de interferência }\end{array}$ & $\begin{array}{l}\text { Deposição por fluxo combinado com } \\
\text { predominância de fluxo oscilatório } \\
\text { relacionado a ação de onda de } \\
\text { tempestade em zona de shoreface }\end{array}$ & \multirow[b]{2}{*}{$\begin{array}{l}\text { Rampa média } \\
\text { dominada por } \\
\text { tempestades }\end{array}$} & \multirow[b]{2}{*}{$A F 3$} \\
\hline $\begin{array}{l}\text { Calcário cristalino } \\
(\mathrm{Cm})\end{array}$ & $\begin{array}{l}\text { Acamamento de megamarca } \\
\text { ondulada estratificação de baixo } \\
\text { ângulo; recobrimento de argila no } \\
\text { topo das formas de leito; marcas } \\
\text { onduladas; base das camadas } \\
\text { escavada com marcas de calha de } \\
\text { escala centimétrica. }\end{array}$ & $\begin{array}{l}\text { Migração de barras de submaré sob } \\
\text { correntes trativas com intervalos de } \\
\text { água calma }\end{array}$ & & \\
\hline $\begin{array}{l}\text { Calcário cristalino } \\
(\mathrm{Cc})\end{array}$ & $\begin{array}{ll}\text { Laminação } & \text { cruzada cavalgante } \\
\text { supercrítica } & \text { e laminação quase- } \\
\text { planar } & \end{array}$ & $\begin{array}{l}\text { Fluxos oscilatório e combinado } \\
\text { depositando por tração e suspensão }\end{array}$ & \multirow{3}{*}{$\begin{array}{l}\text { Rampa interna } \\
\text { dominada por } \\
\text { maré }\end{array}$} & \multirow{3}{*}{$A F 4$} \\
\hline $\begin{array}{l}\text { Ritimito de calcário } \\
\text { cristalino - pelito } \\
\text { (Rh) }\end{array}$ & $\begin{array}{l}\text { Acamamento heterolítico (estruturas } \\
\text { wavy-flaser, recobrimento de argila, } \\
\text { pares de argila); marcas onduladas } \\
\text { assimétricas }\end{array}$ & $\begin{array}{l}\text { Migração de ondulações com } \\
\text { alternância de tração e suspensão } \\
\text { relacionadas a correntes de maré em } \\
\text { ambiente de submaré }\end{array}$ & & \\
\hline $\begin{array}{l}\text { Calcário cristalino } \\
(\mathrm{Cp})\end{array}$ & $\begin{array}{l}\text { Laminação plano-paralela; marcas } \\
\text { de calha; marcas onduladas } \\
\text { assimétricas; laminação truncada de } \\
\text { baixo ângulo; geometria de canal. }\end{array}$ & $\begin{array}{l}\text { Migração de barra preenchendo } \\
\text { canais de submaré, póssivel } \\
\text { influência de correntes de } \\
\text { longshore }\end{array}$ & & \\
\hline $\begin{array}{l}\text { Ritmito calcilutito - } \\
\text { pelito (Rmp) }\end{array}$ & Camadas tabulares & $\begin{array}{l}\text { Alternância de precipitação } \\
\text { carbonática e deposição de pelitos } \\
\text { em suspenção }\end{array}$ & $\begin{array}{l}\text { Rampa externa } \\
\text { mista carbonato- } \\
\text { siliclástica }\end{array}$ & $A F 5$ \\
\hline $\begin{array}{l}\text { Calcário cristalino } \\
\text { preto }(\mathrm{CCp})\end{array}$ & $\begin{array}{l}\text { Laminação plano-paralela; } \\
\text { laminação truncada por onda; } \\
\text { laminação pinch and swell }\end{array}$ & $\begin{array}{l}\text { Deposição por ação de onda } \\
\text { induzida por tempestades em zona } \\
\text { de shoreface; ocasionalmente } \\
\text { liquefação }\end{array}$ & \multirow{2}{*}{$\begin{array}{l}\text { Rampa interna } \\
\text { estromatolítica } \\
\text { influenciada por } \\
\text { onda }\end{array}$} & \multirow[t]{2}{*}{$A F 6$} \\
\hline $\begin{array}{l}\mathrm{M} \text { i c r o b i a } 1 \\
\text { boundstone }(\mathrm{Mb})\end{array}$ & $\begin{array}{l}\text { Estromatolitoscolunares, localmente } \\
\text { ramificados, com laminação interna } \\
\text { convexa }\end{array}$ & Atividade microbiológica & & \\
\hline $\begin{array}{l}\text { Calcário cristalino } \\
\text { preto }(\mathrm{Cc})\end{array}$ & Laminações convoluta e planar & $\begin{array}{l}\text { Deposição rápida em superfície } \\
\text { inclinada seguida por deformação } \\
\text { causada por movimentação dos } \\
\text { sedimentos incosolidados sob a } \\
\text { influência de gravidade }\end{array}$ & $\begin{array}{l}\mathrm{R} \text { a } \mathrm{m} \quad \mathrm{p} \text { a } \\
\mathrm{c} \text { arbonátic } \\
\mathrm{e} x \mathrm{t} \text { e } \mathrm{r} \text { n a } \\
\text { inclinada }\end{array}$ & $A F 7$ \\
\hline Siltito (S1) & Laminado a maciço & Deposição por suspensão & \multirow{2}{*}{$\begin{array}{l}\text { Offshore de } \\
\text { p l a t a for m a } \\
\text { siliciclástica }\end{array}$} & \multirow{2}{*}{$A F 8$} \\
\hline Marga (Mm) & Maciça & Deposição por suspensão & & \\
\hline Arenito (Am) & Maciço & Correntes de turbidez & $\begin{array}{l}\text { Prodelta - } \\
\text { frente deltaica }\end{array}$ & $A F 9$ \\
\hline
\end{tabular}


LO

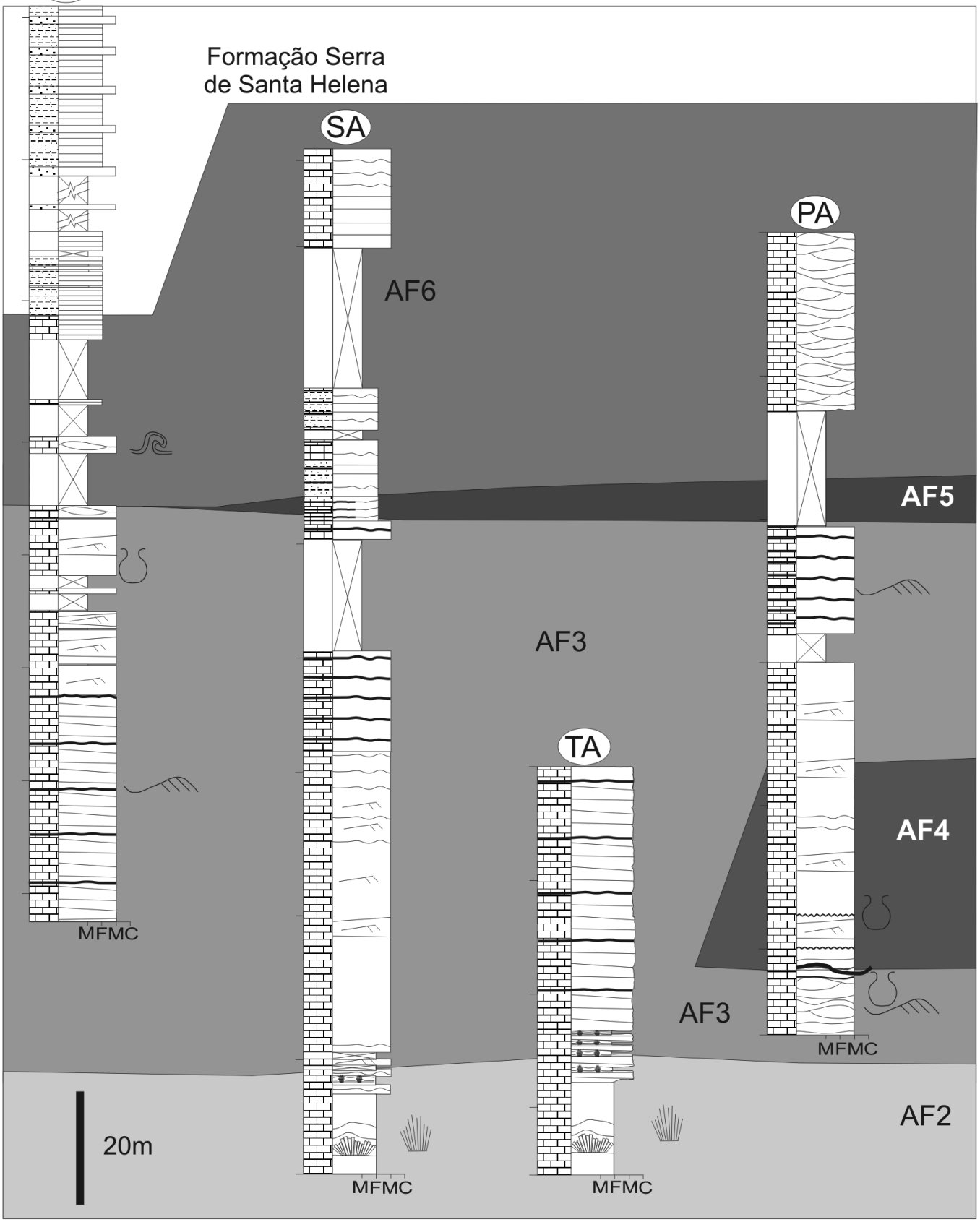

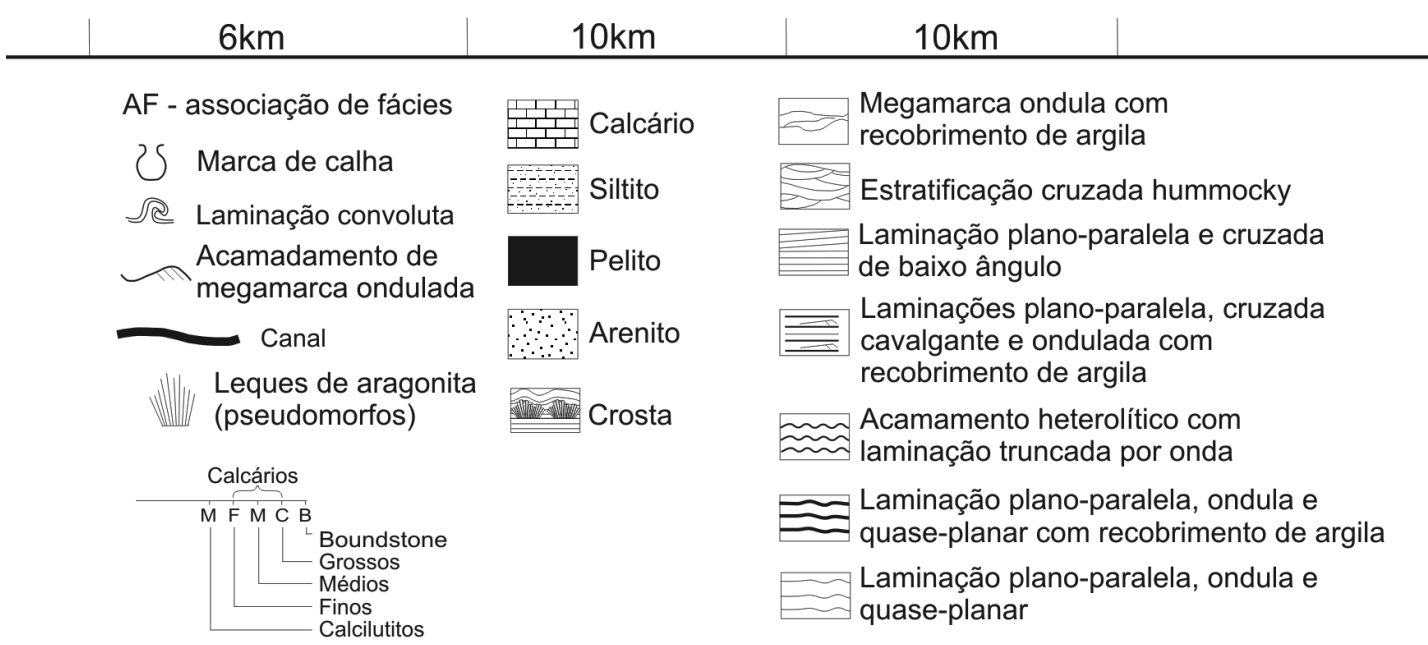

Figura 2 - Seções LO, SA, PA e TA. Associações de fácies e correlações. 

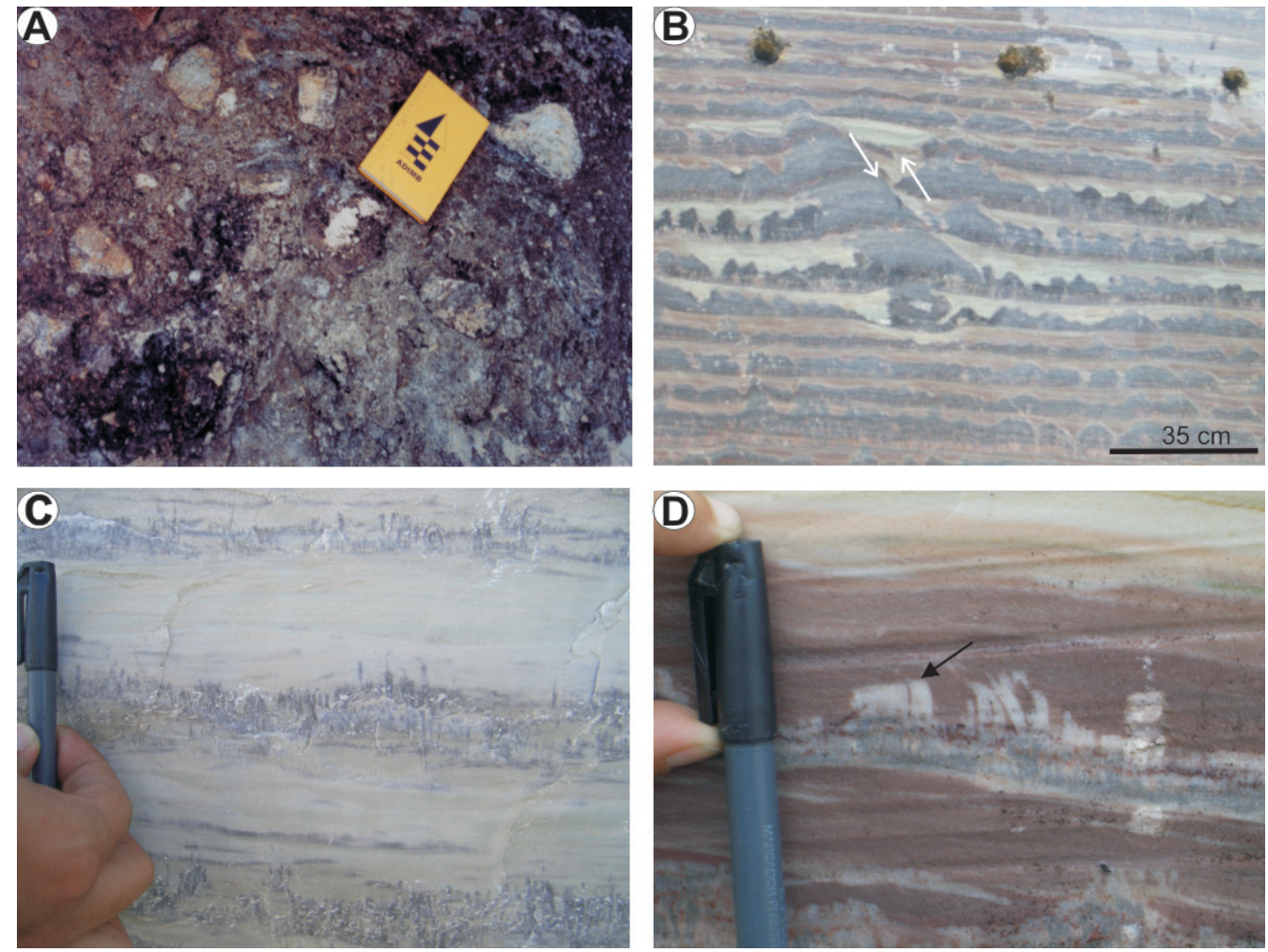

Figura 3 - Feições das associações de fácies 1 e 2. (A) conglomerado polimítico com seixos arredondados a angulares de quartzito, gnaisse e carbonato. Em B e C a tampa de caneta mede $4 \mathrm{~cm}$ de comprimento, em $D$ a caderneta mede $18 \mathrm{~cm}$ de comprimento. (B) ciclos de escala centimétrica com intercalações de calcilutito e leques de cristais de calcita (pseudomorfos de aragonita) deslocados por falha sinsedimentar (seta). (C) cristais pseudomorfos de aragonita cinza-escuro com morfologia acicular e terminações retilíneas. Note a laminação ondulada nas camadas de micrito acima dos leques de cristais. (D) sobrecrescimento diagenético branco dos cristais (seta).

velmente equivalentes à discordância basal do Grupo Bambuí na área estudada e não podem ser correlacionadas a essa AF1.

Rampa supersaturada em $\mathrm{CaCO}_{3}$ (AF2) Acima do Conglomerado Carrancas e sobrepondo o embasamento do Cráton do São Francisco em recobrimento em onlap, uma importante transgressão é registrada por deposição de carbonatos a partir de águas supersaturadas em $\mathrm{CaCO}_{3}$.

Depósitos de rampa carbonática com indícios de supersaturação em $\mathrm{CaCO}_{3}$ são encontrados nas seções CR, SA, TA e MG, o que implica em extensão lateral de escala regional (Fig. 2). Esses depósitos formam camadas tabulares em sucessões de até $30 \mathrm{~m}$ de espessura, organizadas em ciclos de escala centimétrica de calcilutito (Mp fácies) e leques de cristais de calcita (Mc fácies), sendo esses interpretados como pseudomorfos de aragonita (Fig. 3c). Abundância de leques de cristais constitui a feição mais marcante da sucessão de carbonatos Sete Lagoas. Os cristais pseudomorfos de aragonita são pretos a cinza escuro. Esses cristais possuem morfologia acicular com terminações retilíneas, formando leques, com até $15 \mathrm{~cm}$ de altura, que nucleiam a partir da base e adquirem forma radial em direção ao topo da camada, lateralmente conectados a crostas milimétricas de cimento (Fig. 3c). As camadas de cristais são cobertas por calcilutito cinza claro ou vermelho com laminação plano paralela ou ondulada, que acompanham a superficie irregular do topo dos cristais subjacentes, formando níveis frequentemente truncados por estilólitos. A morfologia dos leques e o fato de que na maioria dos lugares as camadas de micrito superpõem os leques de cristais em onlap, indicam que essas feições são primárias e não um registro diagenético. Em alguns lugares, entretanto, cunhas de sobrecrescimento dos cristais intersectam a camada superior de pseudomorfos de aragonita, truncando a laminação dos níveis de calcilutito superiores. Esses sobrecrescimentos são interpretados como uma modificação diagenética, evidenciados por sua cor branca ou vermelha em afloramento (seta na Fig. 3d). Ocasionalmente, feições deformacionais são observadas nas camadas de cristais, compreendendo falhas sinsedimentares que deslocam as camadas de calcilutito/cementstone por alguns centímetros (seta na Fig. 3b), além de inclinação dos tufos de cristais para oeste. O decréscimo na freqüência dos leques de cristais em direção ao topo tanto na seção SA quanto na TA, é acompanhado pela substituição de micrito da fácies Mp por calcários cristalinos terrígenos 
com laminação quase planar a cruzada cavalgante truncada por onda da fácies $\mathrm{Cc}$.

A distribuição da AF2 por centenas de quilômetros quadrados na área estudada sugere um ambiente de rampa sem grande atividade de correntes fortes no estágio inicial da sucessão Sete Lagoas. Essa interpretação é reforçada pela ocorrência dos leques de cristais preservados. De fato, esses leques estão concentrados em camadas sem evidências de ação de ondas de tempo bom ou de tempestade, corroborando a idéia de um ambiente abaixo do limite de onda e tempestade ou em zona protegida (laguna ou plataforma barrada). O crescimento de cristais de aragonita no fundo oceânico tem sido atribuído a ambientes de plataforma profunda associados à supersaturação em $\mathrm{CaCO}_{3}$ no oceano (p.ex. James et al. 2001, Sumner 2002). Os ciclos periódicos de precipitação de calcilutito/cementstone podem implicar em recorrência de eventos de supersaturação. A diminuição dos leques de cristais em direção ao topo das seções, acompanhada pelo aumento de estruturas de onda sugere uma progressiva mudança de ambiente de águas profundas supersaturadas em $\mathrm{CaCO}_{3}$ para ambientes mais energéticos, moderadamente profundos, que caracterizam a transição para a AF3.

Rampa média dominada por tempestade (AF3) A rampa média dominada por ondas de tempestade compreende duas fácies compostas por calcário cristalino com estratificação cruzada hummocky (Ch) e acamamento de megamarca ondulada $(\mathrm{Cm})$.

As fácies Ch e Cm são mais bem expostas nos 20 m inferiores da seção PA (Fig. 2). Essas fácies correspondem a um conjunto de camadas onduladas de calcário cristalino cinza e vermelho com recobrimento de argila (Fig. 4a). Estratificação cruzada hummocky (comprimento de até $1,5 \mathrm{~m}$ ) é observada, associada a laminações do tipo pinch and swell, quase-planar, plano-paralela e subordinadamente estratificação cruzada swaley. Vistos em planta, os domos da estratificação cruzada hummocky apresentam marcas onduladas com padrão de interferência (Fig. 4b). Esses depósitos gradam lateralmente para a fácies $\mathrm{Cm}$, a qual exibe acamamento de megamarca ondulada com estratificação cruzada de baixo ângulo separada por recobrimento de argila. As camadas são caracterizadas por base planar a erosiva, com freqüente ocorrência de marcas de calha. A associação de fácies AF3 sobrepõe os depósitos de água profunda da AF2. Além de suceder os depósitos da AF2, observa-se uma recorrência das fácies que compõem a AF3 sobrepondo a AF5.

A granulação grossa dos depósitos e a presença constante de grãos terrígenos (até 10\%) associada com vários tipos de estruturas (planar, hummocky e swaley) sugerem fácies carbonáticas de alta energia. A presença de estratificação cruzada hummocky e estruturas de onda associadas indicam fluxo combinado relacionado à tempestade (Cheel \& Leckie 1993). Os níveis de partição por lama sugerem deposição em shoreface inferior. As formas de leito de grande escala com morfologia preservada e base escavada (marcas de calha) indicam migração periódica de megamarcas onduladas ou barras sob ação de corrente com alternância de suspensão e eventos esporádicos de tempestade.

Rampa interna dominada por maré (AF4) A rampa interna com domínio de maré é composta por três fácies compostas por calcário cristalino com laminações quase-planar e cruzada cavalgante supercrítica (Lc - Fig. 4c), laminação plano-paralela (Lp - Fig. 4e) ou formando ritimito com pelito (Rh - Fig. 4d).

A fácies Rh é caracterizada por acamamento heterolítico de ritimito de calcário cristalino vermelho com pelito. Essa fácies é observada exclusivamente na seção PA, distribuída em camadas tabulares de até 40 $\mathrm{cm}$ de espessura, cuja extensão lateral supera uma centena de metros. As principais estruturas identificadas foram wavy-flaser, pares de argila e marcas onduladas assimétricas. $\mathrm{O}$ acamamento plano é caracterizado por forte regularidade de recobrimento de argila separando delgadas e espessas lâminas de calcário, interpretados como pares de argila (Fig. 4d). A fácies Rh alterna ou é intercalada com calcários cristalinos com estratificação plano-paralela (fácies $\mathrm{Cp}$ ), algumas vezes preenchendo canais. Os canais apresentam dezenas de metros de largura e menos que cinco metros de profundidade, são assimétricos com base plana-erosiva delineada por recobrimento de argila, e alguns deles apresentam flanco preservado. O preenchimento é concordante com o fundo e com os flancos, com atenuação grafual dos mergulhos em direção ao topo. Localmente, marcas de calha erodem a laminação plana (Fig. 4e). Sobrepondo as fácies $\mathrm{Rh}$ e $\mathrm{Cp}$ ocorre a fácies $\mathrm{Cc}$, caracterizada por camadas de calcário com laminação cruzada cavalgante (com até $20 \mathrm{~cm}$ de espessura - Fig. 4c) intercaladas com níveis de calcário com laminação quase-planar.

A presença de camadas heterolíticas indica alternância entre tração e suspensão controlada por correntes de maré. $\mathrm{O}$ arranjo regular das camadas de ritimito é interpretado como conseqüência da alternância entre águas calmas e correntes, provavelmente relacionadas com ciclos diários de maré cheia e maré vazante, sendo as camadas espessas separadas por níveis de pelito correspondentes aos ciclos de maré mais alta. Esses depósitos são interpretados como registro de deposição de intermaré em rampa interna. Canais migratórios preenchidos por calcários de baixio com laminação planoparalela, foram incisados provavelmente na zona de submaré. Algumas camadas pouco espessas com leques de cristais foram encontradas associadas a esses depósitos de intermaré, interpretados como eventos de supersaturação em uma baía restrita.

Rampa externa mista carbonato-siliciclástica (AF5) Os depósitos de rampa externa da $A F 5$ compreendem ritimitos de calcilutito cinza-pelito (Rmp). A fácies Rmp é formada pela alternância entre carbonato e pelito, alcançando mais de $20 \mathrm{~m}$ de espessura (Fig. 5 e $6 a, b)$. As camadas individuais variam de 2 a $15 \mathrm{~cm}$ de espessura. Esses depósitos registram uma segunda fase de deposição em água profunda, com abundância de siliciclásticos finos depositados abaixo da base onda- 

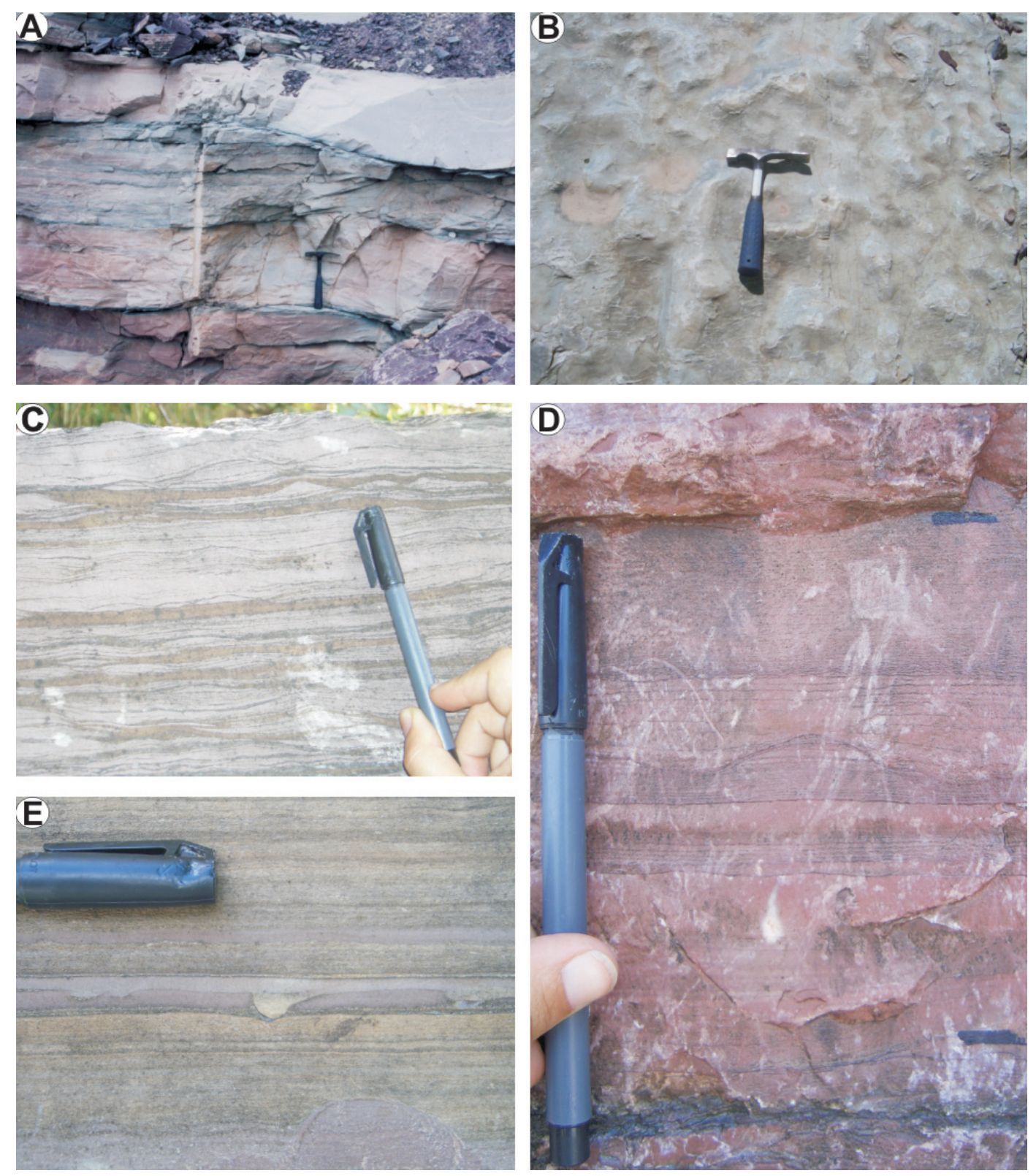

Figura 4 - Feições distintivas das associações de fácies 3, 4 e 5. (A) camadas onduladas com truncamento de baixo ângulo de calcário cristalino cinza e vermelho separadas por recobrimento de argila. (B) marcas onduladas com padrão de interferência, as quais ocorrem sobre o domo da hummocky. (C) laminação cruzada cavalgante contornada por recobrimento de argila. (D) recobrimento de argila separando lâminas finas e espessas de calcário formando pares de argila no ritimito de maré. E) laminação plano-paralela erodida por marca de calha de escala centimétrica. Em A e B o martelo mede $35 \mathrm{~cm}$ de comprimento; em C, D e E a tampa de caneta mede $4 \mathrm{~cm}$ de comprimento.

tempestade. Além disso, a falta de estruturas de onda e a presença de calcários cristalinos laminados (originalmente calcilutito) rico em matéria orgânica corroboram uma transgressão, a qual contrasta fortemente com a primeira transgressão registrada na sucessão Sete Lagoas pela falta de evidências de supersaturação e pela maior espessura das camadas.

Rampa interna estromatolítica influenciada por onda (AF6) Os ritimitos da AF5 gradam lateralmente para a espessa sucessão de depósitos de rampa inter- na da AF6, os quais compreendem calcários cristalinos pretos com estruturas de onda (Ccp) e biolitito (Mb). Essa é a associação de fácies mais expressiva na área de estudo, alcançando mais de uma centena de metros de espessura em algumas sessões, principalmente no setor sudeste da área de estudo (Fig. 5).

A fácies Ccp é caracterizada por laminação truncada por onda (comprimento de onda de até $60 \mathrm{~cm}$ e $5 \mathrm{~cm}$ de altura) com laminação interna ondulada formando estruturas do tipo pinch and swell. As camadas individuais, com até $15 \mathrm{~cm}$ de espessura, apresentam 


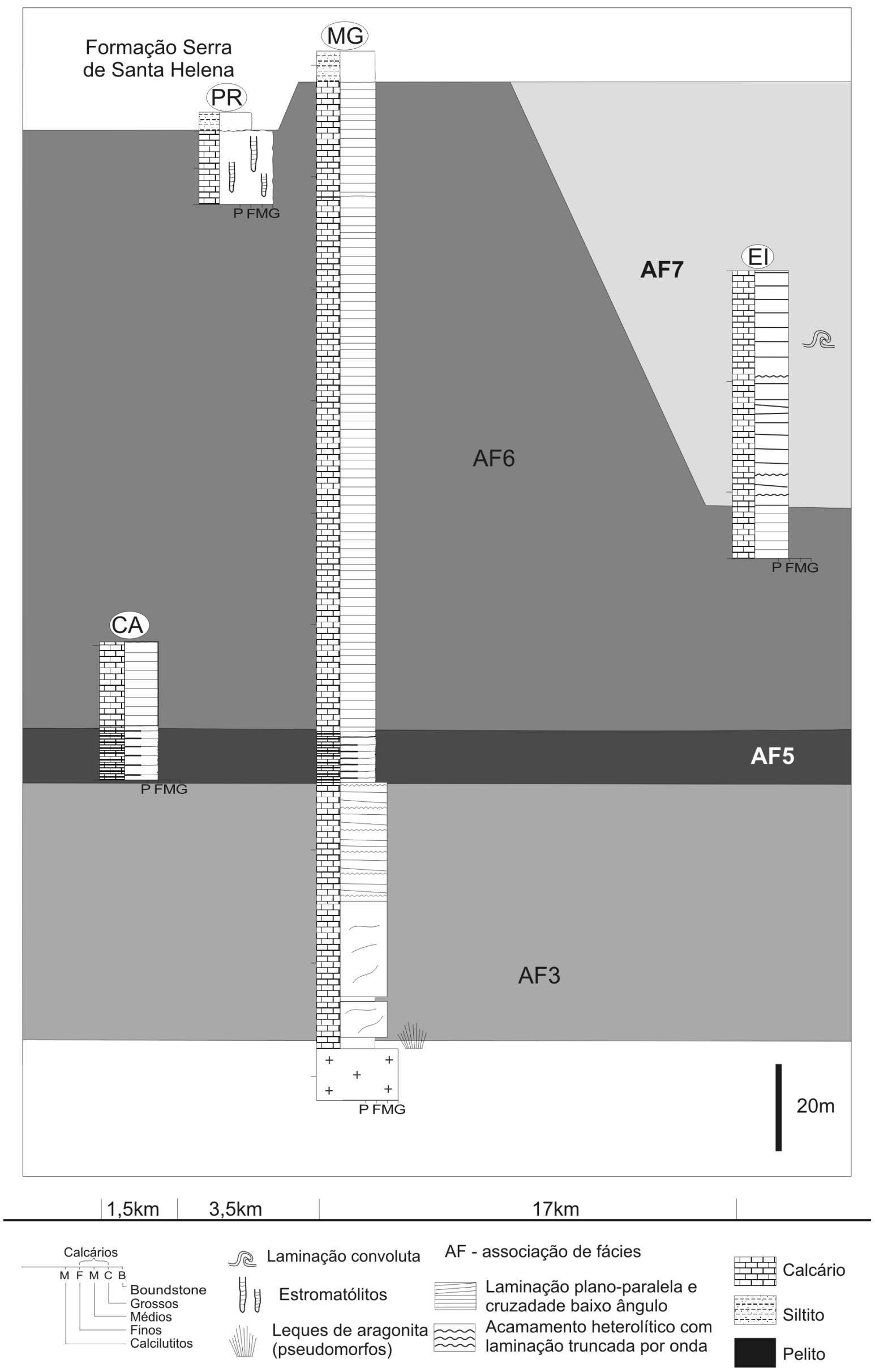

Figura 5 - Seções CA, PR, MG e EI. Associações de fácies e correlações. 

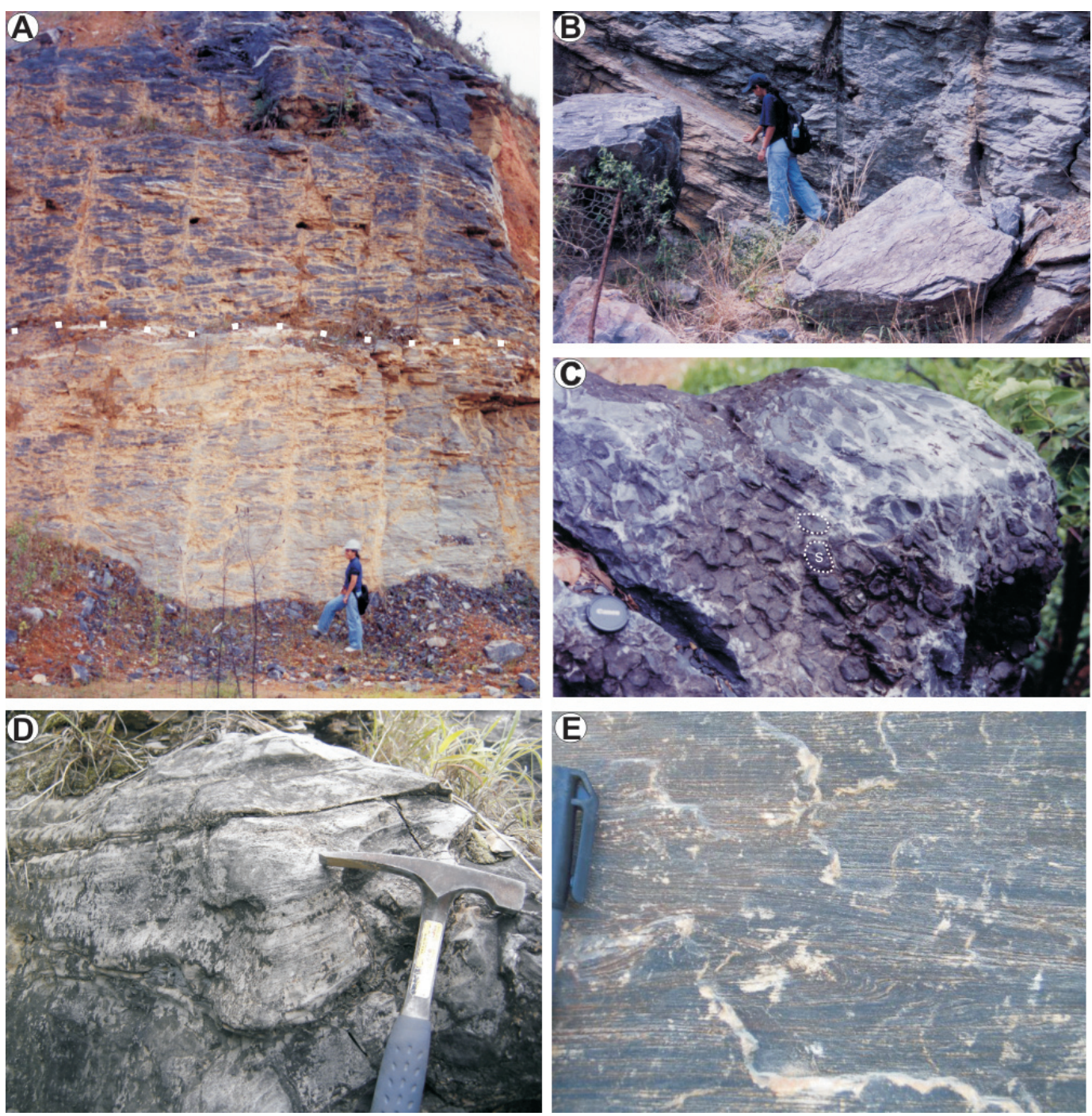

Figura 6 - Feições características das associações de fácies 5, 6 e 7. (A) Contato (linha pontilhada) entre o ritimito de calcilutito-pelito da AF5 com o calcário cristalino preto da AF6 na seção CA. (B) ritimito de calcilutito-pelito da AF5 na seção $M G$. (C) estromatólitos colunares (S) vistos em planta (os círculos pontilhados delimitam duas colunas). (D) $e$ (E) calcário cristalino preto com laminação convoluta. Em A e B a pessoa mede 1,55 m de altura, em $C$ a capa de lente mede $6 \mathrm{~cm}$ de diâmetro, em $E$ a tampa de caneta mede 4 cm de comprimento.

marcas de calha de pequena escala na base. Acamamento convoluto ocorre localmente. A fácies $\mathrm{Mb}$ foi observada apenas na seção PR (Fig. 5) e corresponde a estromatólitos colunares cinza escuros a pretos, raramente ramificados (Fig. 6c). As colunas individuais medem até $40 \mathrm{~cm}$ e podem ter até $10 \mathrm{~cm}$ de diâmetro com laminação interna convexa. Em seção transversal, as colunas expõem uma morfologia poligonal; os espaços intercolunares foram preenchidos por calcilutito preto ou localmente brechas carbonáticas. A ocorrência constante de laminações truncadas por onda e planares sugere ação de onda (p.ex. Harms et al. 1982), provavelmente induzida por tempestades na zona de shorefa$c e$. Processos de liquefação são atribuídos ao impacto de ondas em sedimentos inconsolidados. A colonização de esteiras microbianas em zonas de baixa energia com deposição de lama carbonática está relacionada à ambiente raso de submaré ou laguna. Localmente, o colapso das construções estromatolíticas gerou brechas intraformacionais preenchendo depressões intercolunares. Essa associação de fácies ocorre no topo do segundo ciclo progradacional.

Rampa carbonática externa inclinada (AF7) Os depósitos de rampa carbonática externa da $A F 7$ são compostos por calcários cristalinos pretos da fácies $\mathrm{Cc}$. Essa fácies é caracterizada por laminação plano-paralela, lateralmente passando a ondulação de muito baixo ângulo, e dobras de escorregamento. Os níveis com estruturas convolutas variam de 2 a $10 \mathrm{~cm}$ (Fig. 6d,e), os quais ocorrem esporadicamente, intercalados aos níveis com laminação planar compondo espessos depósitos. 
As recorrentes dobras de escorregamento sugerem uma deposição rápida em uma superfície inclinada, seguida por deformação causada pelo movimento dos sedimentos inconsolidados sob a influência de gravidade. Essa associação de fácies corresponde a depósitos de água profunda no mesmo estratigráfico da $A F 6$, depositada abaixo da base de onda.

Vale ressaltar que calcários cristalinos pretos com laminação planar são encontrados na $A F 6$ e $A F 7$ (compreendendo as fácies $\mathrm{Ccp}$ e $\mathrm{Cc}$ ) e esses depósitos podem alcançar juntos até $160 \mathrm{~m}$ de espessura. A obliteração de estruturas primárias por recristalização dificulta a individualização dessas duas fácies no campo e, conseqüentemente, a estimativa da espessura de cada uma delas separadamente.

Offshore de plataforma siliciclástica (AF8) Na área de estudo, a sucessão carbonática correspondente à Formação Sete Lagoas, é coberta por depósitos siliciclásticos da Formação Serra de Santa Helena. Considerando que essa unidade não é objeto de estudo deste trabalho, são descritas apenas as fácies em contato com os depósitos da Formação Sete Lagoas, com o objetivo de contextualizar a transição estratigráfica de uma unidade para a outra. Dentro desse escopo foram identificadas duas associações de fácies $A F 8$ e $A F 9$.

Uma espessa sucessão de siltitos e margas constitui a $A F 8$ e registra a principal mudança ambiental entre as formações Sete Lagoas e Serra de Santa Helena. Os siltitos ocorrem em camadas de até $1 \mathrm{~m}$ de espessura, maciços ou com laminação plano-paralela. Delgados níveis de marga (até $35 \mathrm{~cm}$ de espessura) ocorrem intercalados às camadas de siltito na base da sucessão, desaparecendo após os quatro metros iniciais do registro de sedimentação da Formação Santa Helena. A formação desses depósitos de granulação fina deu-se por suspensão em águas profundas abaixo do nível de base onda-tempestade, possivelmente a partir de um sistema deltáico.

Prodelta - frente deltáica (AF9) Em uma seção mais proximal, uma sucessão dominada pela $F A 8$ é coberta por camadas de arenito fino maciço, de até $2 \mathrm{~m}$ de espessura, intercalados com camadas de siltitos maciços ou laminados de escala métrica. Os arenitos maciços são interpretados como depósitos correntes de turbidez, possivelmente em um contexto de retrabalhamento de depósitos de frente deltáica para águas mais profundas. Assim, a passagem transicional da $A F 8$ para $A F 9$ é interpretada aqui como o resultado progradação, com a sobreposição de depósitos de arenosos provindos de uma frente deltáica sobre os depósitos plataformais mais distais.

MODELO DEPOSICIONAL E EVOLUÇÃO DA RAMPA CARBONÁTICA SETE LAGOAS Na porção sul do Cráton do São Francisco, a Formação Sete Lagoas alcança mais de $200 \mathrm{~m}$ de espessura, compreendendo dois ciclos de caráter retrogradacional-progradacional que registram a interação entre as taxas de subsidência, oscilação eustática e deposição de carbo-

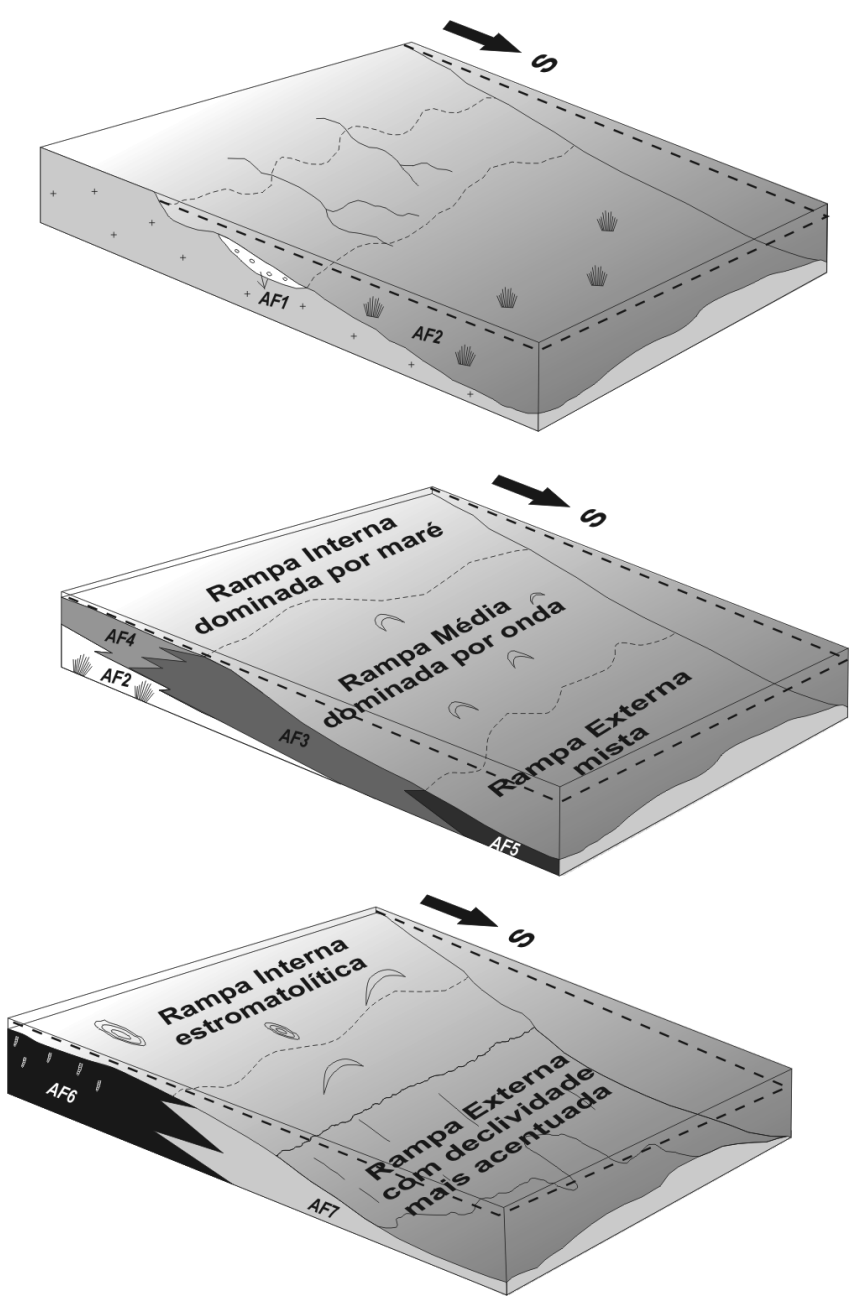

Figura 7 - Blocos-diagrama esquemáticos mostrando o modelo deposicional de rampa carbonática, proposto para a Formação Sete Lagoas.

natos em uma rampa. Admite-se que o modelo de rampa carbonática é o que melhor representaria as associações de fácies caracterizadas e sua paleogeografia. A figura 7 apresenta reconstituições paleogeográficas derivadas desse modelo, em três diferentes estágios de evolução da rampa carbonática. O reconhecimento de superfícies com significado cronológico e as variações nos padrões de empilhamento das associações de fácies levaram ao reconhecimento de tratos de sistemas deposicionais e serviram de base para a correlação das vinte seções estratigráficas medidas. Foram definidas três seqüências deposicionais na área de estudo, das quais duas correspondem as sucessões Carrancas-Sete Lagoas e uma à Formação Serra de Santa Helena.

Em linhas gerais, as interpretações paleoambientais revelam um cenário de rampa rasa à profunda com depocentro na margem sudeste do Cráton do São Francisco, como é indicado pelo aumento na espessura de depósitos de água profunda acompanhado de adelgaçamento dos depósitos de água rasa (Fig. 8). A ocorrência de depósitos influenciados por tempestade e maré sugere uma conexão com o oceano, e a presença de espessa sucessão de águas rasas sugere uma bacia 


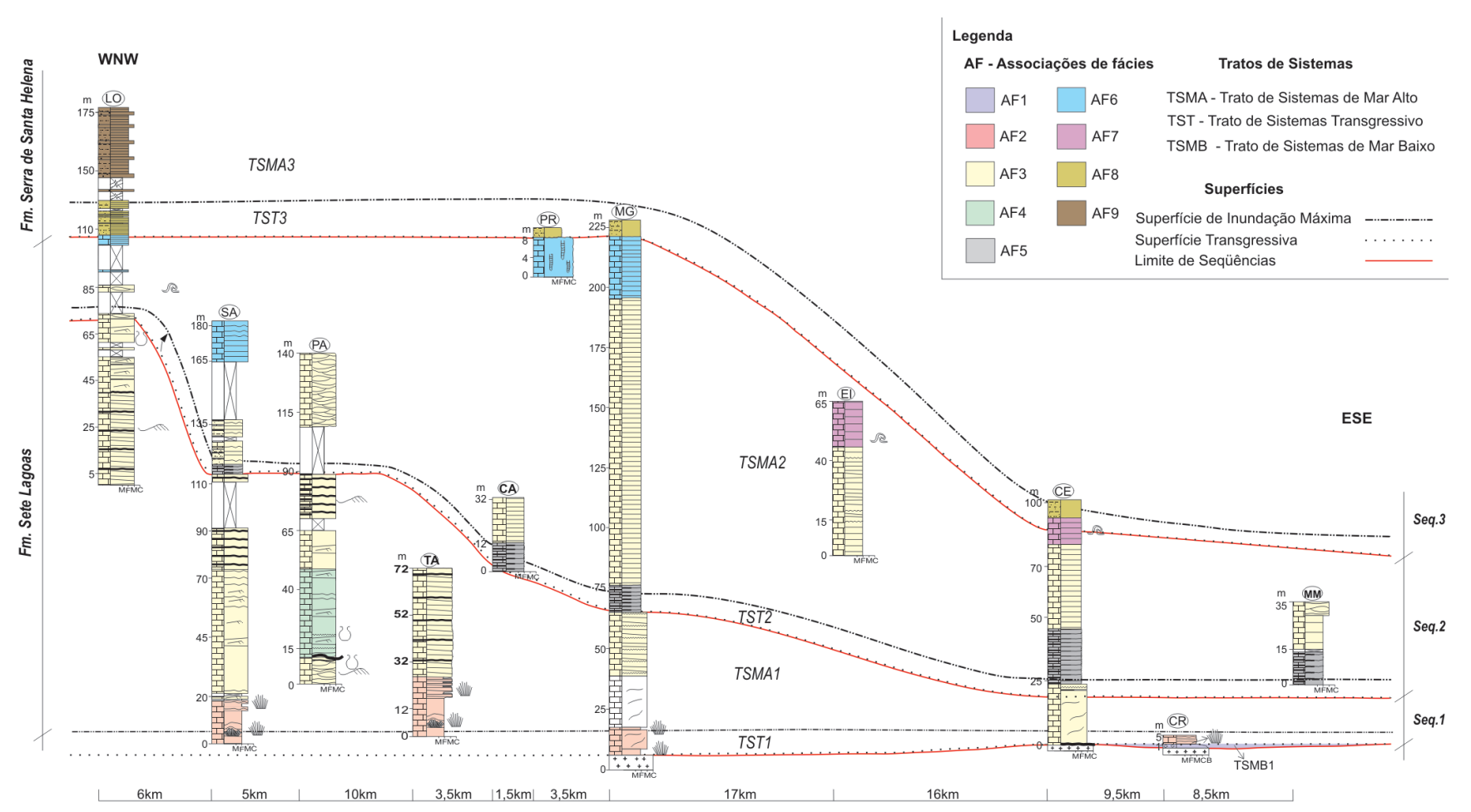

Figura 8 - Composição das seções estratigráficas da Formação Sete Lagoas, mostrando associações de fácies, estruturas sedimentares, tratos de sistemas, superficies estratigráficas e sua correlação ao longo de um perfil WNW-ESE na Bacia do Bambuí.

fortemente subsidente.

Seqüiência 1 A ocorrência isolada da $A F 1$ diretamente acima da discordância basal com os gnaisses paleoproterozóicos registra deposição dentro de canais de escala métrica incisados antes da primeira transgressão importante. A composição dos clastos do conglomerado indica como fontes o embasamento e erosão de sucessões carbonáticas previamente depositadas, sugerindo um episódio de queda do nível de base e exposição subaérea (limite de seqüências 1 - LS1). Portanto, o preenchimento das esparsas depressões acima do limite de seqüências 1 por material de granulação grossa é interpretado como uma pequena parte restante do registro do primeiro trato de sistema de mar baixo (TSMB1), depositado durante taxas lentas de subida do nível do mar.

Uma abrupta mudança das fácies de granulação grossa da $A F 1$ para uma sucessão dominada por fácies compostas por calcilutito e leques de cristais de calcita da $A F 2$, atribuídas a deposição em águas supersaturadas em $\mathrm{CaCO}_{3}$, marca uma pronunciada transgressão sobre o Cráton do São Francisco, delimitando a superfície transgressiva (ST1) e o início do primeiro trato de sistema transgressivo (TST1). As águas supersaturadas em $\mathrm{CaCO}_{3}$ possibilitaram a periódica nucleação de precipitados no assoalho marinho, incluindo leques de cristais e crostas, cobertos por calcilutito. Regionalmente, a ST1 está amalgamada com o LS1 de tal forma que em duas das seções medidas a ST1 repousa diretamente sobre o embasamento paleoproterozóico. Diminuição no tamanho dos cristais acompanhada por aparecimento de calcários com estruturas de onda (originalmente formados por fragmentos na fração areia), marcam o início de um ciclo progradacional, delimitando a superfície de inundação máxima (SIM1)dessa seqüência deposicional. Esse ciclo de progradação, caracterizado como um trato de sistemas de mar alto (TSMA1), é marcado por predomínio de depósitos influenciados por ondas de tempestade $(A F 3)$, com passagem local para as fácies de ritimitos de maré da $A F 4$, sugerindo progradação de ambientes de rampa interna restrita sobre a rampa média.

Seqüência 2 A sucessão de águas rasas do TSMA1 é abruptamente interrompida por uma superfície de relevo irregular recoberta pelos depósitos de água profunda da $A F 5$, sugerindo interrupção na sedimentação e início de um novo ciclo deposicional. Dessa forma, superfície que limita o TSMA1 é interpretada como um limite de seqüências deposicionais. A ausência de superfícies erosivas ou de exposição possivelmente decorre de uma queda do nível relativo do mar não suficiente para superar a taxa de subsidência nessa porção da bacia. A segunda seqüência deposicional inicia-se com o registro de uma transgressão (TST2) que afogou a rampa, indicando que a superfície transgressiva (ST2) encontra-se amalgamada ao LS2. Esse TST2 é caracterizado 
por ritimitos da $A F 5$, nas seções distais (a leste), e um ciclo granodecrescente ascendente de calcário preto nas seções proximais (a oeste), indicando uma migração dos ambientes deposicionais em direção ao continente. Esse segundo trato de sistemas transgressivo difere daquele da seqüência mais antiga, pois suas fácies de água profunda são caracterizadas por deposição mista carbonato-siliciclástica e ausência de precipitados inorgânicos.

A superfície de inundação máxima da segunda seqüência deposicional (SIM2) é demarcada por espesso nível pelítico em todas as seções, indicando águas profundas com baixas taxas de deposição de carbonato, em decorrência da ausência de organismos plantônicos com carapaças carbonáticas no Neoproterozóico. Acima desse nível pelítico ocorre a sucessão progradacional do TSMA2, caracterizada por calcários cristalinos com estruturas de onda de tempestade depositados em rampa média $(A F 3)$. A deposição em ambiente águas profundas e possivelmente anóxico foi favorável à preservação de matéria orgânica nos calcários pretos. A parte superior do TSMA2 compreende o registro de ambientes costeiros, de rampa interna, desenvolvidos após o progressivo raseamento da bacia, formando depósitos de onda de tempo bom e de tempestade, associados às construções microbiais (AF6). Um progressivo aumento no ângulo de inclinação da rampa, decorrente de maiores taxas de sedimentação das porções proximais, possibilitou a deposição de sedimentos com estruturas de escorregamento da $A F 7$, registrando a evolução do sistema para uma rampa mais inclinada.

Seqüência 3 Uma importante mudança de fácies, com fim abrupto na deposição de carbonatos, marca outro limite de seqüência (LS3), e consequentemente o início da seqüência deposicional 3. Provavelmente a LS3 constitui um limite de seqüência de hierarquia superior ao LS1 e LS2. O LS3 coincide com o limite litoestratigráfico entre as formações Sete Lagoas e Serra de Santa Helena.

Os depósitos siliciclásticos de granulação fina da $A F 8$ dominam a porção inferior da seqüência $3 \mathrm{e}$ compreendem o intervalo medido total em todas as seções estratigráficas, exceto a do extremo oeste do perfil (LO). Como não há variação vertical de fácies clara nessa sucessão, é difícil estabelecer onde a retrogradação cessa e a progradação começa. Logo, a exata posição da superfície de inundação máxima (SIM3) que determina o limite superior do TST3 permanece desconhecida.

Apesar da superfície de inundação máxima não ter sido identificada no campo, evidência clara de progradação é dada por uma sucessão granocrescenteascendente medida na seção LO, a qual representa a porção mais proximal, em relação ao continente, da área estudada. Essa seção revela uma transição gradual da $A F 8$ para $A F 9$, indicando um progressivo raseamento em direção ao topo, interpretado como resultado de uma progradação deltáica.

CONCLUSÕES A Formação Sete Lagoas foi depositada em uma rampa carbonática dominada por tempestade, dividida em ambientes de rampa interior, média e exterior. Esse sistema de rampa compreende dois ciclos retrogradacionais-progradacionais que registram a interação entre taxas de subsidência, oscilação eustática e deposição carbonática, caracterizando as duas seqüências estratigráficas. Uma terceira seqüência, siliciclástica, ocorre acima da Formação Sete Lagoas. As três seqüências são compostas por tratos de sistemas transgressivos e de mar alto, com ocorrência local de tratos de sistema de mar baixo na seqüência 1 . As duas primeiras seqüências correspondem a ao Conglomerado Carrancas, somente porção basal da seqüência 1, e Formação Sete Lagoas, maior parte da seqüência 1 e toda a seqüência 2 .

Na seqüência 1, o Trato Transgressivo é caracterizado por deposição de precipitados de aragonita, cobertos por calcilutitos, depositados em ambiente restrito ou, alternativamente, abaixo do nível de base de ondas de tempestade. Acima desses ocorrem depósitos de rampa exterior, caracterizados por ritimitos de calcário-pelito, sem pseudomorfos de precipitados de aragonita, já pertencentes ao Trato de Ssitemas de Mar Alto. Esse ciclo progradacional continua com depósitos de rampa média, nos quais a deposição de carbonato foi essencialmente dominada por tempestades, enquanto a deposição na rampa interior foi dominada por marés.

Na seqüência 2, o Trato Transgressivo é caracterizado por ritimitos pelito-calcilutito de rampa externa, que passam para um Trato de Mar Alto composto por depósitos de rampa média influenciada por ondas e rampa interna com estromatólitos no topo da sucessão Depósitos de rampa externa mostram uma evolução progressiva de rampa carbonática com baixo ângulo para uma rampa distalmente mais inclinada durante a última fase de deposição da Formação Sete Lagoas.

Agradecimentos Os autores agradecem as sugestões apresentadas pelos dois revisores designados pela revista. Este trabalho é parte daTese de Doutorado da primeira autora e contou com o apoio da CAPES (442/04) e da FAPESP (processos 03/08716-3 e 05/53521-1).

\section{Referências}

Allen P.A. \& Hoffman P.F. 2005. Extreme winds and waves in the aftermath of a Neoproterozoic glaciation. Nature, 433: 123-127.

Alvarenga C.J.S., Santos R.V. \& Dantas E.L. 2004. C-O-Sr isotopic stratigraphy of cap carbonates overlying Ma- rinoan-age glacial diamictites in the Paraguay Belt, Brazil. Precambrian Res., 131: 1-21.

Babinski M., Van Schmus W.R. \& Chemale F. 1999. Pb$\mathrm{Pb}$ dating and $\mathrm{Pb}$ isotope geochemistry of Neoproterozoic carbonate rocks from the São Francisco basin, 
Brazil: implications for the mobility of $\mathrm{Pb}$ isotopes during tectonism and metamorphism. Chem. Geol., 160: 175-199.

Babinski M., Kaufman A.J. \& Varni M. 2003. First Direct Dating of a Neoproterozoic Post-Glacial Cap Carbonate. In: South American Symposium on Isotope Geology, 4, Short Papers, p. 321-323.

Costa M.T. \& Branco J.J.R. 1961. Introdução. In: J.J.R. Branco (ed.) Roteiro para excursão Belo Horizonte-Brasília. Congresso Brasileiro de Geologia, 14, Belo Horizonte, Anais, SBG, p. 1-119.

Cheel R.J. \& Leckie D.A. 1993. Hummocky cross-stratification. Sed. Review, 1: 103-122.

D’Agrella-Filho M.S., Babinski M., Trindade R.I.F., Van Schmus W.R. \& Ernesto M. 2000. Simultaneous remagnetization and $\mathrm{U}-\mathrm{Pb}$ isotope resetting in Neoproterozoic carbonates of the Sao Francisco craton, Brazil. Precambrian Res., 99: 179-196.

Dardenne M.A. 1978. Síntese sobre a estratigrafia do Grupo Bambui no Brasil Central. In: SBG, Congr. Bras. Geol., 30, Recife. Anais, v. 2, p. 597-610.

Evans D.A.D. 2000. Stratigraphic, geochronological, and paleomagnetic constraints upon the Neoproterozoic climatic paradox. Am. J. Sci., 300: 347-433.

Halverson G.P., Maloof A.C. \& Hofman P.F. 2004. The Marinoan glaciation (Neoproterozoic) in northeast Svalbard. Basin Res., 16: 297-324.

Harms J.C., Southard J.B., Walker R.G. 1982. Structures and sequences in clastic rocks. Society for Sedimentary Geology (SEPM) Short Course 9, 249 pp.

Hoffman P.F., Kaufman A.J., Halverson G.P. \& Schrag D.P. 1998. A Neoproterozoic snowball Earth. Science, 281: 1342-1346.

Hoffman P.F. \& Schrag D.P. 2002. The Snowball Earth hypothesis: testing the limits of global change. Terra Nova, 14: $129-155$.

James N.P., Narbonne G.M. \& Kyser T.K. 2001 Late Neoproterozoic cap carbonates: Mackenzie Montains, northwestern Canada: precipitation and global glacial meltdown. Can. J. Earth Sci., 38: 1229-1262.

Jiang G.N., Christie-Blick N., Kaufman A.J., Banerjee D.M. \& Rai V. 2004. Carbonate platform growth and cyclicity at a terminal Proterozoic passive margin, Infra Krol Formation and Krol Group, Lesser Himalaya, India. Sedimentology, 50: 921-952.

Karfunkel J. \& Hoppe A. 1988. Late Proterozoic glaciation in central-eastern Brazil: synthesis and model. Palaeogeo., Palaeoclim., Palaeoeco., 65: 1-21.

Kennedy M.J. 1996. Stratigraphy, sedimentology, and isotopic geochemistry of Australian neoproterozoic postglacial cap dolostones: Deglaciation, $\delta^{13} \mathrm{C}$ excursions, and carbonate precipitation. J. Sed. Res., 66: 1050-1064.

Kennedy M.J., Christie-Blick N. \& Sohl L.E. 2001. Are Proterozoic cap carbonates and isotopic excursions a record of gas hydrate destabilization following Earth's coldest intervals? Geology, 29: 443-446.

Machado N., Noce C.M., Belo de Oliveira O.A. \& Ladeira E.A. 1989. Evolução geológica do Quadrilátero Ferrífero no Archeano e Proterozóico Inferior, com base em geocronologia U-Pb. In: Simp. Geol. Núcleo Minas Ge- rais, 5; Simp. Geol. Núcleo Brasília, 1, Belo Horizonte. Anais, SBG, p. 1-5

Marshak S. \& Alkmim F.F. 1989. Proterozoic contraction/ extension tectonics of the southern São Francisco region, Minas Gerais, Brazil. Tectonics, 8: 555-571.

Martins-Neto M.A., Pedrosa-Soares A.C. \& Lima S.A.A. 2001. Tectono-sedimentary evolution of sedimentary basis from Late Paleoproterozóico to Late Neoproterozóico in the São Francisco craton and Araçuaí fold belt, eastern Brazil. Sed. Geol., 141-142: 343-370.

Misi A. \& Veizer J. 1998. Neoproterozoic carbonate sequences of the Una Group, Irecê Basin, Brazil: Chemostratigraphy, age and correlations. Precambrian Res., 89: 87-100

Narbonne G.M. \& Aitken J.D. 1995. Neoproterozoic of the Mackenzie Mountains, northwestern Canada. Precambrian Res., 73: 101-121.

Nogueira A.C., Riccomini C., Nóbrega Sial A., Veloso Moura C.A. \& Fairchild T.R. 2003. Soft-sediment deformation at the base of the Neoproterozoic Puga cap carbonate (southwestern Amazon craton, Brazil): Confirmation of rapid icehouse to greenhouse transition in snowball Earth. Geology, 31: 613-616.

Pedrosa-Soares A.C., Cordani U.G. \& Nutman A. 2000. Constraining the age of Neoproterozoic glaciation in eastern Brazil: First U-Pb (SHRIMP) data of detrital zircons. Rev. Bras. Geoc., 30: 58-61.

Peryt T.M., Hoppe A., Bechstadt T., Koster J., Pierre C. J. \& Richter D.K. 1990. Late proterozoic aragonitic cement crusts, Bambui Group, Minas Gerais, Brazil. Sedimentology, 37: 279-286.

Pimentel M. M., Fuck R.A. \& Botelho N.F. 1999. Granites and the geodynamic history of the Neoproterozoic Brasília Belt, Central Brazil: A Review. Lithos, 46(3): 463-483.

Romeiro-Silva P.C. \& Zalán P.V. 2005. Contribuição da sísmica de reflexão na determinação do limite oeste do Cráton do São Francisco. In: III Simpósio sobre o Cráton do São Francisco, Short Papers, p. 44-47.

Santos R.V., Alvarenga C.J.S., Dardenne M.A., Sial A.N. \& Ferreira V.P. 2000. Carbon and oxygen isotope profiles across Meso-Neoproterozoic limestones from central Brazil: Bambui and Paranoá groups. Precambrian Res., 104: 107-122.

Sumner D.Y. 2002. Decimetre-thick encrustations of calcite and aragonite on the sea-floor and implications for Neoarchaean and Neoproterozoic ocean chemistry. In: W. Altermann \& P.L. Corcoran (eds.), Precambrian sedimentary environments: A modern approach to ancient depositional systems, International Association of Sedimentologists, Special Publication, v.33, pp.: 107-120.

Uhlein A., Trompette R.R. \& Alvarenga C.J.S. 1999. Neoproterozoic glacial and gravitational sedimentation on a continental rifted margin: The Jequitaí-Macaúbas sequence (Minas Gerais, Brazil). J. South Am. Earth Sci., 12: $435-451$.

Manuscrito CSF-11 Submetido em 31 de maio de 2006 Aceito em 01 de março de 2007 